\title{
Knowledge Management Platform for Online Training
}

\author{
http://dx.doi.org/10.3991/ijac.v8i3.4907 \\ Ramona Oros ${ }^{1}$, Andreas Pester ${ }^{1}$ and Caterina Berbenni-Rehm ${ }^{2}$ \\ ${ }^{1}$ Carinthia University of Applied Sciences, Villach, Austria \\ 2 PROMIS@Serv S.à.r.l., Luxembourg, Luxembourg
}

\begin{abstract}
In our rapidly changing world where technology is continuingly being updated and altered, the learning process should (must) be continual as well. To ensure the highest quality of work performance, there are three requirements: 1) clearly structured learning processes; 2) well-organized and structured learning; and 3) knowledge and skill pools. These are especially necessary for novel and rapidly changing technologies such as online engineering. This paper will present an implementation option of how to structure remote labs knowledge using PROMIS ${ }^{\circledR}$, a knowledge and process management platform.
\end{abstract}

Index Terms-knowledge management system, learning, remote labs, PROMIS.

\section{INTRODUCTION}

The current rapid advancement of new technologies on the market is calling for well-prepared engineers. Because of this, engineering education must be continuously updated and developed. To adapt to these ever-changing market requirements, the learning process of engineers is permanent and oriented to online solutions. Wide usages of e-learning facilities are needed to support pedagogical and practical perspectives of learning. Essential in engineering training is the experimental component or set up of a practical experiment to proof or reject initial hypothesis.

In this framework, the challenge is to find qualified resources from which to gain high quality knowledge.

A wealth of different sources of information is available over the Internet but this does not mean that they are well documented and/or well structured. For this reason a significant number of consortia are attempting to offer successful solutions for online learning.

\section{EU EXPERIENCE}

The experience of Carinthia University of Applied Science team has significantly increased over the last 10 years and has been gained in teaching engineers online. For that a knowledge base structure that has the possibility to create an online engineering environment suitable for rewarding qualification. The team was and is still involved in several EU projects providing materials and courses for online learning in technical fields for EU and non-EU countries [3], [4]. The courses have different level of difficulty and are oriented towards technical/vocational schools, universities and training at the work place.

All materials developed have high quality information and important knowledge transfer potential. They include new technological solutions and their potential use in the market. Case studies and best practices are presented frequently and continuously so that the learner can correlate to actual and practice oriented situations.

The main aim of these projects has been to modernize the engineering learning experience with innovative ICT technologies and educational methods at a pedagogical and professional level. The main focus of the approach of the CUAS team was and is to combine the materials with online lab exercises. To get claim more knowledge about "Online Engineering" and "online Experiments", one study program and several courses were developed. But in that field the knowledge is changing so fast, that it is better to structure the knowledge in a knowledge base, which is renewed periodically.

Two important project examples of contributions to Online engineering training programs are "E-pragmatic" E-Learning and Practical Training of Mechatronics and Alternative Technologies in Industrial Community (www.e-pragmatic.eu ended in 2012) and "iCo-op" Industrial Cooperation and Creative Engineering Education based on Remote Engineering and Virtual Instrumentation (www.ico-op.eu still under development). The goal was to enhance in-company training of professionals from industries and vocational institutions in engineering in EU and non-EU countries. "E-pragmatic" was an EU funded project. The main aim of the project was to modernize mechatronics and engineering vocational training of employed professionals, apprentices and trainees by enhancing the existing or establishing new in-company training approaches [1], [2]. To accomplish this objective, a training program was organized using a multifunctional and multilingual learning portal and had about 30 different courses. At the same time these activities were used to foster the development of networks of professionals for sharing knowledge, information and expertise. The same portal which was used for the learning space was also used as a discussion and sharing space for social networking. In spite of the effort engaged in this endeavour, a significant number of potential users could not participate because of a lack of time, different format requirements of the learning materials and, most importantly, language issues. At this level the training was preferred to be in mother language of the individuals.

In "iCo-op", the experiences of previous projects were used as well as a more concrete study over the performance and methods to offer online learning experiences. The project is striving to support university-enterprises partnerships in Armenia, Georgia, and Ukraine through modernizing engineering education based on remote engineering and virtual instrumentation enhanced with trans- 
versal knowledge and competences at universities; and offering contemporary methods of the vocational education and training for adults in enterprises to enrich the participants' knowledge for successful careers and individual self-development.

The most relevant aspects are presented in the following section.

\section{StATE Of The ART}

Over the last 10 years the most centralized online information related to practical experience in the field of engineering has been merged into repositories and this is an on-going process.

One of these repositories is "Lab2go" (www.lab2go.net), developed by an EU-funded project: OntoWiki. This is a repository that offers different laboratory providers a common framework to collect and describe laboratory data located all over the world. The most important aim of this repository is to facilitate the search process to interest users and this is being done using Semantic Web technology. Currently, in addition to the English version, Portuguese and French versions are available as well [5]. Thus, languages barriers are being minimized and the resources are more profitably used.

Similar repositories based on the same approach have been developed by LILA (www.library-of-labs.org - under http://www.lila-project.org/ ) and by the University of Bordeaux (http://elab.creea.u-bordeaux1.fr/ELAB).

The main disadvantage of repositories in general is that their structure is not knowledge-oriented. In these repositories the information is structured as learning applications; thus, the information cannot be connected to a (information) management system and offered in a straightforward way to the persons directly interested. In order to structure the information more efficiently, a special web semantic for online labs has been developed, tested and improved over the years.

\section{ONLINE ENGINEERING WEAKNESES}

For e-learning in general and especially for learning at the work place, as it is the case for Small and medium sized Enterprises (SME), a well-structured knowledge system is mandatory. For SMEs, the information should be well structured, presented in a clear manner, up-to-date and combined with functionalities like eConsulting and eMentoring [6] in one integrated system. This knowledge system should include both information about ongoing developments and projects, as well as information about best-practice-examples.

The idea of sharing the information in an organized way has led to the creation of networks of online labs for engineers. This has proven to be a feasible solution for the short term only. For long term solutions these networks became repositories without any real knowledge interaction.

This was the main reason to organize the knowledge about online labs for engineering in a knowledge management system. The aim of this was to be able to use the information not only for pedagogical purposes but also for in-company training.

A state of the art study/investigation in the field of knowledge management databases or platforms shows varied solutions. Most of the platforms follow the idea of a centralized repository for information with additional interaction capabilities. In some cases the platform is treated as a machine-readable resource used for the dissemination of information, generally online, or with the capacity to be put online. Only few solutions offer the possibility of organized knowledge and provide personalized access through a management system. Solutions that possess such characteristics are not open source nor are they available as free trial solutions.

The weakness of learning/teaching online engineers has to be organized as knowledge on demand in such a way that offers an efficient knowledge overview adaptable to personal competences and skills.

\section{V. $\quad$ PROMIS $^{\circledR}$}

A solution that integrates the facilities of a Knowledge Management and an Integrated Management System is offered by PROMIS $\AA$. This is a Software-as-a-Service and intranet platform of interactive services, which is considered by the European Commission as the system that, at present, best answers the requirements of Open Innovation [7], [8].

PROMIS ${ }^{\circledR}$ offers organizations and consultants the possibility to structure their knowledge in an effective multilevel pyramidal structure that can be connected to an integrated management system. This knowledge management system has two directions: one business oriented and the other educational and training oriented.

The eBusiness approach aims at supporting the creation of alliances between institutional and private stakeholders. To this end it offers a toolbox to structure their knowledge, content, and training and additionally to generate interactive services to be shared or sold to other interested parties. In the field of online engineering the cooperation between public bodies, research (mostly state funded), telecommunication services providers and private companies is essential.

eTraining represents the solution oriented in supporting a lifelong learning process. Using this Open Innovation, platform, dedicated information is made accessible to the user in an interactive collaboration and eMentoring mode, which improves the level of knowledge quickly and effectively.

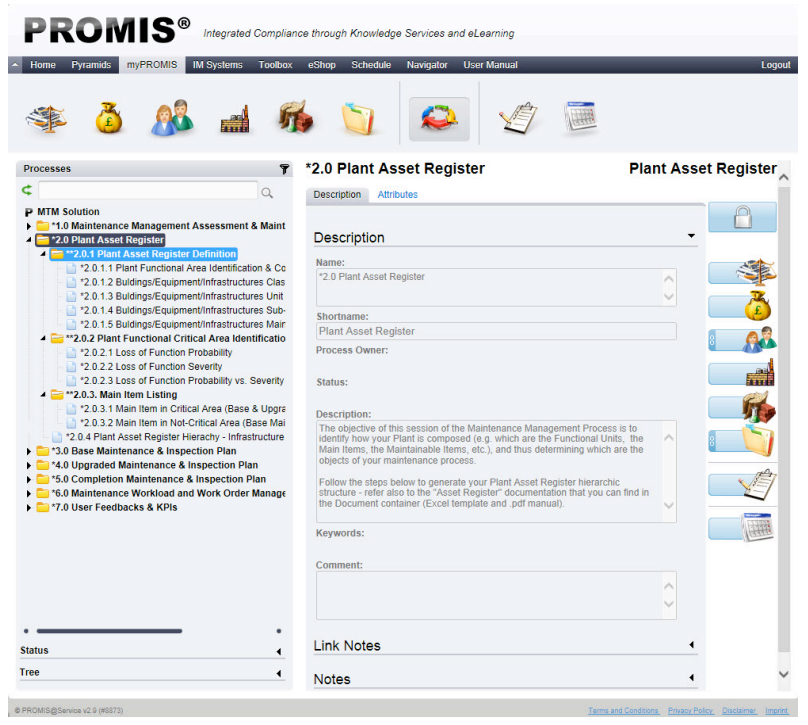

Figure 1. PROMIS $^{\circledR}$ interface 
In addition, a pyramidal structure is suggested to support the structure of information and knowledge in both cases. In the 'pyramid' the information can be structured in multilevel, vertical and horizontal approaches. In such a way individuals, experts, associations or institutions can structure their knowledge in specific topics, fields, or domains in one or more of the PROMIS ${ }^{\circledR}$ pyramids.

Afterwards, the content of the pyramid can be easily linked to a management system and directly connected to the relevant personnel. Base on personal skills and competence the training material is assign. In this way the learning time is efficentilized.

The most important advantage of the pyramid is that the information can be translated automatically in different languages; currently, with the support of professional translation systems this information can be translated immediately in 56 languages. Having learning material in their respective native language represents an important motivational fact to all users.

\section{ICO-OP - PYRAMID OF REMOTE LABS}

A CUAS research team using the pyramid structure of PROMIS ${ }^{\circledR}$ for organizing knowledge was able to develop a system that provides users with information about remote labs from three different perspectives divided into three main topics. This pyramid was filled in with knowledge collected from the experience gained through different European projects and collaborative work with partners from more than ten countries. Best practice in the field and valuable demonstrations are presented as well. The purpose of this work is to provide the best knowledge that we have gathered and gained about remote labs to the iCo-op project.

By using the facilities of the PROMIS ${ }^{\circ}$ pyramid, the iCo-op project is attempting to support the universityenterprises partnerships in Armenia, Georgia, and Ukraine through modernizing engineering education based on remote engineering and virtual instrumentation enhanced with transversal knowledge and competences at the universities. Offering contemporary methods of vocational education and training for adults in enterprises will enrich participants' knowledge to enable more successful careers and self-development. The developed knowledge base was developed inside this project, but aims to be general and applicable in other environments. Also is the structure chosen in such a way, that it is easy to up-date and to adapt to different applications.

The pyramid has a standard structure of three sides. On each side the information is structured on horizontal levels and vertical sectors. For remote labs the sides of the pyramid are represented by the fields of usage: project work, research and SME activities. On all sides the information is structured top-bottom under the same levels:

- Entrance - this section contains welcome and general information about online labs and groups interest in the field from CUAS

- Online lab conceptions - this sections contains particular information from each field regarding the way that online labs can be used, which are the trends and utility; the exemplification is made through videos and best practice from CUAS and partners universities
- Remote Labs - here the information is concentrated on remote labs as one important part of online labs and offers clear inputs about technologies used at CUAS and partners universities, solutions developed during the last years

- Software based Labs Management - the information presented in this section is more particular and address specific software and implementation solutions for online labs

- Specific technical solutions - this section is an extension of the previous one and includes also hardware implementation solutions. The bases of this section are the already existing lab solutions: WebLab Deusto, GOLDI lab Ilmenau, Remote Labs using LabVIEW Villach, LabSocket Brasov.

As well from left to right cells knowledge information is structured from theoretical aspects to practical ones through three subdivisions: concepts, videos and best practice.

In small business cases the managers can provide independent learning/ training sessions for their employees. Managers can predefine the access to different knowledge sections depending on the personal qualifications needed for each individual user. Thus, the resulting access is directly guided to the relevant section(s), which in turn eliminates many time consuming procedures.

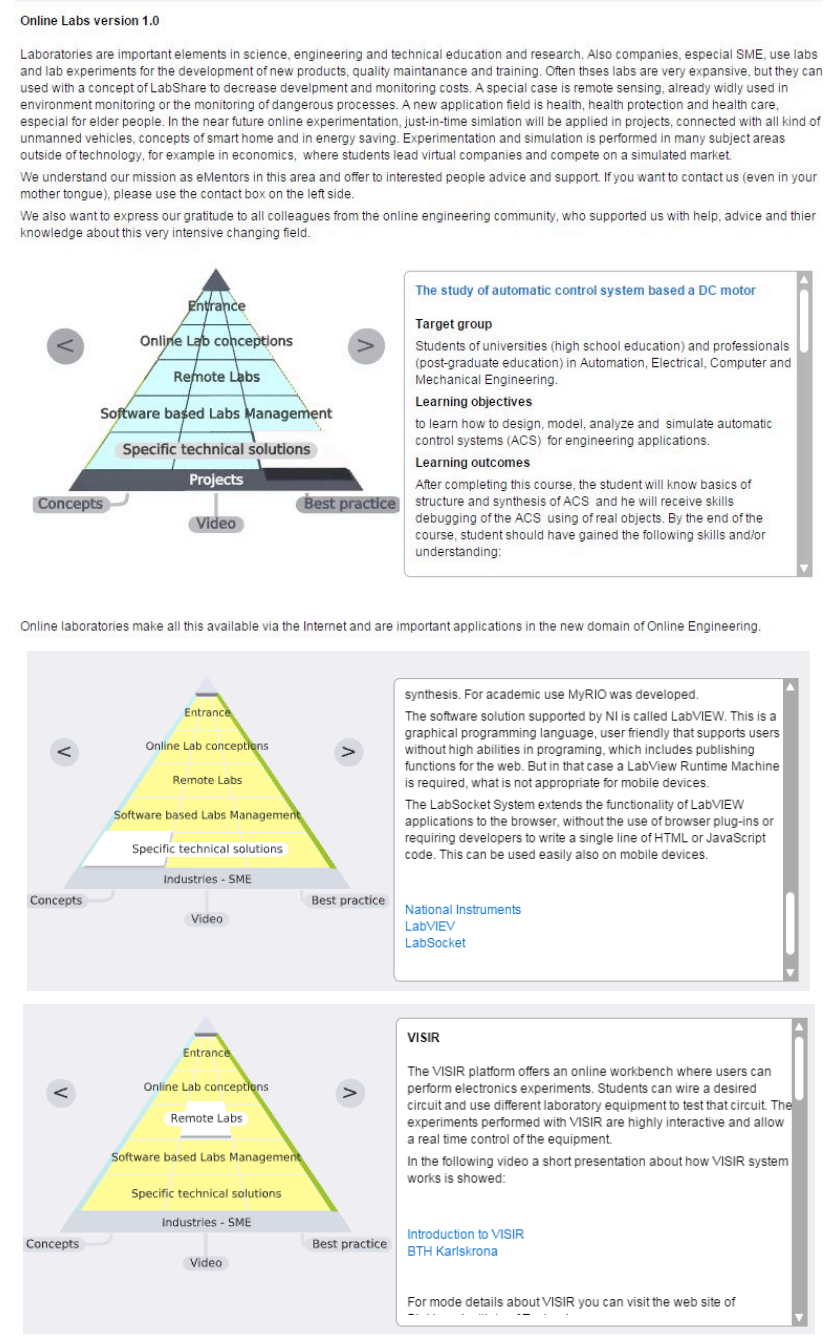

Figure 2. Online labs pyramidal approach 


\section{CONCLUSION AND FURTHER DEVELOPMENTS}

The use of a structural knowledge platform represents a key advantage for accessing qualified information for pedagogical and/or self-development learning. The solution offered by PROMIS ${ }^{\circledR}$ transforms learning in a cost effective process for all users: managers / teachers / students / employees. For this purpose new pyramids will be developed in order to enrich online engineering practice experiments with National Instruments and GALUDI applications.

"PROMIS® is not a mere service or product; it is much more a 'living organism' and an instrument to make knowledge a tangible asset. "[Berbenni-Rehm]

\section{REFERENCES}

[1] Pester, A.; Rojko, A.; Maier, C. (2011) Distance training of Mechatronics and Alternative technologies in European industry, International conference on e-learning on workplace, ICELW

[2] Rojko, A.; Pester, A.; Jezernik, K.; (2011) International EPRAGMATIC network for adult engineering education, IEEE Global Engineering Education Conference (EDUCON), Amman, Jordan, pp. 34-39 http://dx.doi.org/10.1109/EDUCON.2011. $\underline{5773109}$

[3] P. Andreas, O. Ramona, D. Olga (2013).Explorative Learning with technology in STEM - the OLAREX experience. ICL 2013, Kazan, Russia

[4] P. Andreas, O. Ramona, D. Olga (2013).OLAREX: Initiating Secondary Schools Teachers into Online Labs Experience for Teaching. ECEL 2013, Sophia Antipolis, France

[5] P. Andreas, O. Ramona (2013).iLab based remote labs as an approach for collaborative learning in STEM subjects. ICBL 2013, Florianopolis, Brazil

[6] C. Berbenni-Rehm, A. Druta, R. Gowland, R. Busch, "Communities of Knowledge in the Daily Life of an SME - The PROMIS ${ }^{\circledR}$ Example", eChallenges 2-2012 Conference Proceedings, Paul Cunningham and Miriam Cunningham (Eds), IIMC International Information Management Corporation, 2012 ISBN: 978-1905824-35-9

[7] European Commission, DG for RESEARCH \& INNOVATION Directorate I - Climate Action and Resource Efficiency, I.2 - Ecoinnovation. Expert workshop 'A Systemic approach to Ecoinnovation' and Conclusions of the Workshop on 2-3 June 2014. Page 22.

[8] New paper. Maintenance Management: PROMIS ${ }^{\circ}$ - whom is it for and where can it be used?

\section{AUTHORS}

Ramona Georgiana Oros has a $\mathrm{PhD}$ degree in engineering and a master in international business administration, and is currently working as junior researcher at Carinthia University of Applied Sciences in the field of remote technologies and online labs. She has been an active part in several international projects, e.g., EICL, Epragmatic, eScience, IC-op, Go-Lab regarding e-learning and the development of online laboratories and internationalization and capacity building in projects as MIMI. During the last years she has participated in international conferences in the field of online labs and learning approaches in education or at the work place. She has been part of the reviewing process of international conferences (REV, ICL), which has represented both a challenge and an acknowledgement. (e-mail: r.oros@fh-kaernten.at).

Andreas Pester is a professor at the Carinthia University of Applied Sciences, Europa Strasse 4, Villach 9254 Austria. He has more than 20 years experience in eLearning in higher education, in strategic planning for using eLearning in higher education and in platform evaluation, planning, developing, implementation and evaluation of curricula in higher education on undergraduate and graduate level (including international master programs), in teaching math and mathematical modeling, simulation technologies, remote engineering, online labs. He has been a Guest Professor at UPC Barcelona, UMaribor, UNESP Bauru (Brazil and been involved in more than 11 EU and national projects in eLearning. He has more than 80 publications, been a member of the program committees of different international conferences and is the editor-in-chief of the online-journal "Advanced cooperate learning”. (e-mail: a.pester@fh-kaernten.at).

Caterina Rehm-Berbenni holds a PhD in modern Philology at the University of Bergamo. She started her marketing career at FERRERO OHG Germany (6 years), followed by the responsible direction of an organization with cultural exchange in Europe with 153 people and has more than 25 years experience in international marketing as well as Knowledge \&Technology Transfer. She was CEO of FUTUREtec GmbH for 14 years, leading an interdisciplinary team of experts in the fields of information technology, technology and knowledge transfer from research to SMEs, market research and development, marketing strategies, deployment plans and activities, and project management. Since 2008 she has been the CEO of PROMIS@Service, (www.promis.eu) a young company based in Luxembourg, which assists European SMEs and their stakeholders to deal with a complex regulatory environment, to structure processes and data in a systematic way, and to achieve de facto compliance with legal requirements and the major international norms and standards. She specializes in Open Innovation, knowledge intensive services, knowledge structure and transfer, measuring the value of non tangibles from a methodological viewpoint \& human/machine perspective in Cloud/SaaS environments; communities of knowledge, eLearning and e-Business, collaborative working environments, multilingualism, international marketing as well as intercultural and cross-cultural issues. She is a recognised thought leader and keynote speaker at international conferences and chair of EU panels; past vice-chair of the high-level advisory group DG Research for SMEs; member of the Ethical Review; advisory member of AI\& Society (Artificial Intelligence and Society) of Springer Verlag; ILNAS expert for the ISO TC 176. Additionally, she has nine international publications. (e-mail: caterina.berbenni-rehm@promisatservice.eu ).

The work described above has been, among others, performed within the framework of the following EC funded projects:

(i) " iCo-op - Industrial Cooperation and Creative Engineering Education based on Remote Engineering and Virtual Instrumentation (No. 530278- TEMPUS-1-2012-DE-TEMPUS -JPHES) http://www.icoop.eu/;

(ii) PROMISLingua - PeRformance Operational and Multilingual Interactive Services to support Compliance for SMEs in Europe - GA: CIP-ICT-PSP-270913 - www.promislingua.eu, 2011 - 2013; deployPROMIS - Process Oriented integrated quality Management Internet Services and eLearning for SMEs, eTEN Initial Deployment, GA 046303, 2007 - 2008;

(iii) PROMIS: PRocess Oriented integrated quality Management Internet Services for SMEs. Coordinator, C 26402, eTEN, 2000-2001 https://Www.promis.eu.

The opinions expressed by the authors do not necessarily reflect the position of the European Community, nor does it involve any responsibility on its part.

This article is an extended and modified version of a paper presented at the International Conference on E-learning in the Workplace 2015 (ICELW'15), held in June 2015, at Columbia University in New York, NY, USA. Submitted 15 March 2015. Published as resubmitted by the authors 20 July 2015. 